\title{
Factors associated with the perceived benefits and barriers to physical activity in liver cirrhosis
}

\author{
Marcela Rodrigues de Siqueira $\odot$, Fábio Heleno de Lima Pace ${ }^{\circledR}$, \\ Tuany Mageste Limongi ${ }^{3} \odot$, Diane Michela Nery Henrique ${ }^{\circledR}$, \\ Pedro Augusto de Carvalho Mira ${ }^{3,4} \odot$, Túlio Medina Dutra de Oliveira ${ }^{5} \odot$,

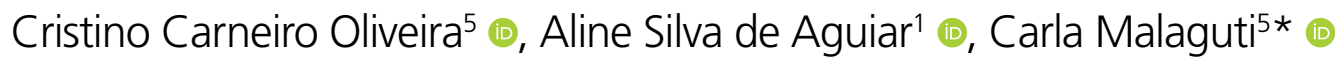

\section{SUMMARY}

OBJECTIVE: To analyze the sociodemographic and clinical factors associated with the perceived benefits and barriers to physical activity (PA) in subjects with liver cirrhosis.

METHODS: This cross-sectional study assessed 102 outpatients with liver cirrhosis regarding the clinical and sociodemographic profile and the perceived benefits and barriers to PA by the Exercise Benefits and Barriers Scale and muscle strength. A Generalized Step-Forward linear regression analysis was used to identify the factors associated.

RESULTS: The participants were $59 \pm 10$ years and $60.8 \%$ were men. Around $29.4 \%$ had ascites decompensation. Perceived benefits and barriers were associated with the presence of ascites $(95 \% \mathrm{Cl}-0.079-0.03 ; \mathrm{p}=0.06$ and $95 \% \mathrm{Cl} 0.003-0.217 ; p=0.045$, respectively). In the group with ascites, both benefits and barriers were associated with muscle strength. In the group without ascites, benefits were associated with cardiovascular risks and no association was observed with barriers to physical activity.

CONCLUSIONS: Perceived benefits and barriers to physical activity are associated with intrinsic factors such as the presence of ascites and cardiovascular risk in individuals with liver cirrhosis. The results of this study highlight key elements that must be considered for increasing physical activity in this population.

KEYWORDS: Health promotion. Liver cirrhosis. Physical activity.

\section{INTRODUCTION}

Cirrhosis is a chronic disease characterized by destruction and abnormal regeneration of the liver parenchyma ${ }^{1}$. The disease accounts for approximately 2 million deaths, making it the 11 th most common cause of death worldwide ${ }^{2}$. The main causes are harmful alcohol consumption, viral hepatitis B and $\mathrm{C}$, and metabolic syndromes related to overweight and obesity ${ }^{3}$.
Two distinct stages of cirrhosis with different prognostic implications have been defined: compensated cirrhosis a stage 4 fibrosis with or without esophageal varicose veins; and decompensated cirrhosis, including variceal bleeding, hepatic encephalopathy, ascites, spontaneous bacterial peritonitis, and/or hepatorenal syndrome ${ }^{4}$. Chronic cirrhosis also affects the musculoskeletal system and leads to a reduction in peripheral muscle mass and

\footnotetext{
'Universidade Federal de Juiz de Fora, Program in Public Health - Juiz de Fora (MG), Brazil.

${ }^{2}$ Universidade Federal de Juiz de Fora, Department of Medical Clinic - Juiz de Fora (MG), Brazil.

${ }^{3}$ Universidade Federal de Juiz de Fora, Program in Physical Education - Juiz de Fora (MG), Brazil.

${ }^{4}$ Universidade Federal Fluminense, Department of Physiology and Pharmacology - Niteroi (RJ), Brazil.

${ }^{5}$ Universidade Federal de Juiz de Fora, Program on Rehabilitation Sciences and Physical Function Performance - Juiz de fora (MG), Brazil.

*Corresponding author: carlamalaguti@gmail.com

Conflicts of interest: the authors declare there are no conflicts of interest. Funding: This study was financed by the Coordenação de Aperfeiçoamento de Pessoal de Nível Superior - Brasil (CAPES) - Finance Code 001. P.A.C.M. was supported by Fundação Carlos Chagas Filho de Amparo à Pesquisa do Estado do Rio de Janeiro (FAPERJ \# E-26/203.037/2018).
}

Received on October 11, 2020. Accepted on October 14, 2020. 
sarcopenia, with consequent exercise intolerance, reduction in functional capacity, and quality of life $\mathrm{f}^{5,6}$.

Regular physical activity has been recommended in the management of chronic diseases and is associated with health benefits and control of disease progression ${ }^{7}$. Although limited data are available on the effect of regular physical activity on liver cirrhosis, recent studies have reported that exercise may preserve muscle mass and reverse sarcopenia, resulting in reduced fatigue, improved physical activity levels, and quality of life ${ }^{6,8}$. A recent systematic review of the literature, including a study in which lifestyle intervention with exercise and diet reduced the hepatic venous pressure gradient, physical exercise did not increase the frequency of adverse events? . Although the benefits of physical activity have been documented in patients with liver cirrhosis, adherence to a more active lifestyle is still low in this patient population.

Benefits of and barriers to physical activity have been described in other clinical populations, but it is still scarce on liver cirrhosis. To increase adherence to physical activity in cirrhosis patients, it is essential to understand their perceptions and behaviors towards physical activity ${ }^{10}$.

The present study aims to identify the sociodemographic and clinical factors associated with perceived benefits of and barriers to physical activity in patients with liver cirrhosis.

\section{METHODS}

This is an observational, cross-sectional study conducted from January to July 2018. A convenience sample of outpatients diagnosed with liver cirrhosis who attended the Hepatology Outpatient Clinic of the Department of Gastroenterology of the University of Juiz de Fora was invited to participate. The study was approved by the institutional Ethical Committee (number 2.494.069). All patients signed a freely informed consent term.

Inclusion criteria were the previous diagnosis of liver cirrhosis made by clinical, laboratory, or histology methods, age $\geq 18$ years and under 70 years. Exclusion criteria were inability to answer the questions, hepatocellular carcinoma, and malignancy, other chronic diseases as immunodeficiency syndromes, end-stage renal disease, neuromuscular diseases, cardiopulmonary disease (except diabetes and controlled systemic arterial hypertension), obesity grade II, or any other condition that presented physical limitations, not due to cirrhosis.

Information sociodemographic were collected from medical records. All respondents were asked about complications related to the disease including ascites decompensation, presence of esophageal varicose veins, and variceal bleeding during the last year, as well as cardiovascular risks (hypertension and diabetes). Additionally, laboratory exams regarding the ChildPugh model ${ }^{11}$ and classification of the disease were accessed from medical records within three months of the interview or according to the responsible physician.

The perceived benefits of and barriers to physical activity were assessed with the EBBS Brazil, a 42-item questionnaire: 14 belonging to the Barrier Scale $\left(\mathrm{EBBS}_{\mathrm{BAR}}\right)$ and 28 to the Benefits Scale $\left(\mathrm{EBBS}_{\mathrm{BEN}}\right)$. EBBS $\mathrm{BEN}_{\mathrm{BN}}$ score was calculated by the sum of 28 items into five domains: biological aspects, physical performance, psychological aspects, social interaction, and preventive health. $\mathrm{EBBS}_{\mathrm{BAR}}$ score was calculated by the sum of 14 items into four domains: time expenditure, physical exertion, exercise milieu, and family discouragement. Higher values indicated greater benefits or perceived barriers ${ }^{12,13}$.

Handgrip strength (HGS) was assessed using the $\mathrm{Jamar}^{\circledR}$ dynamometer this is a valid method for the diagnosis of malnutrition and sarcopenia in patients with cirrhosis ${ }^{14}$. Sarcopenia may be a factor that is associated with barriers to physical activity in this population. Guidelines of the American Society of Hand Therapists were followed ${ }^{15}$. The highest value among the three measurements was considered for analysis.

\section{Statistical analysis}

Data were analyzed using SPSS Statistics version 19.0. KolmogorovSmirnov test was used to test the normality of the data. A descriptive analysis was performed, where continuous variables were summarized as mean $\pm \mathrm{SD}$ and categorical variables as frequency or percentage. Demographic variables, sex, and age were recorded; clinical variables, such as laboratory tests for total bilirubin, albumin, and INR referred to the Child-Pugh model ${ }^{20}$; complications related to the disease in the last year included ascites decompensation, presence of esophageal varicose veins, and variceal bleeding; associated cardiovascular risks (diabetes/hypertension); and handgrip strength. A generalized linear regression analysis using gamma distribution and logarithmic linking functions was used to examine the association between $\mathrm{EBBS}_{\mathrm{BEN}}$ and $\mathrm{EBBS}_{\mathrm{BAR}}$ and independent variables. The level of significance for univariate analysis was set at $\mathrm{p}<0.10$. For multivariate analysis, variables with $\mathrm{p}<0.05$ remained in the model and were included following the step-forward method. The percentage of individuals who strongly agreed or agreed with the barrier/benefit item was analyzed for each question as well as for each domain. Comparisons were made using Student's t-test and Mann-Whitney test, and statistical significance was accepted at $\mathrm{p}<0.05$.

\section{RESULTS}

This study included 102 outpatients. The mean age of the study group was 59.2 years (SD 10.58), 60.8\% were men, 57.8\% were diagnosed with CP-A. The most common disease etiologies were alcohol (38.2\%), hepatitis C (30.4\%), nonalcoholic fatty 
liver disease (21.6\%), and others (9.8\%). In the sample, $48 \%$ had esophageal varicose veins and $29.4 \%$ had ascites decompensation during the last year. At the time of the evaluation, seven patients ( $6 \%$ of all samples) presented ascites, which were classified as Child C. Diabetes and systemic arterial hypertension were present in 43.1 and $57.8 \%$, respectively (Table 1).

EBBS Brazil had good reliability. The reported internal consistency (Cronbach's alpha) for the total, $\mathrm{EBBS}_{\mathrm{BEN}}$, and EBBS $_{\text {BAR }}$ were $0.87,0.90$, and 0.78 , respectively. Using generalized linear regression analysis, it was identified a significant association between ascites, and $\mathrm{EBBS}_{\mathrm{BEN}}$ and $\mathrm{EBBS}_{\mathrm{BAR}}$ (Table 2). Patients were divided into two groups: one group involving patients with had ascites and the other one without ascites in the last year. Then, we analyzed the relationship between benefits of and barriers to physical activity in these groups separately (Table 3 ). In the group with ascites, the $\mathrm{EBBS}_{\text {BEN }}$ (95\%CI 0.001-0.009, $\left.\beta=0.005, \mathrm{p}=0.019\right)$ and EBBS $_{\text {BAR }}(95 \% \mathrm{CI}-0.027--0.003, \beta=0.109, \mathrm{p}=0.016)$ was associated with handgrip strength. In the group with non-ascitic

Table 1. Baseline demographic and clinical characteristics of patients with liver cirrhosis.

\begin{tabular}{|c|c|}
\hline & $\mathrm{n}=102$ \\
\hline Age, years* & $59.20 \pm 10.58$ \\
\hline Gender, F/M (\%) & $62: 40$ \\
\hline \multicolumn{2}{|l|}{ Disease severity } \\
\hline Child-Pugh A, n (\%) & $59(57.8)$ \\
\hline Child-Pugh B/C, n (\%) & $43(42.2)$ \\
\hline \multicolumn{2}{|l|}{ Etiology } \\
\hline Alcohol, n (\%) & $39(38.2)$ \\
\hline $\mathrm{HCV}, \mathrm{n}(\%)$ & $31(30.4)$ \\
\hline NAFLD, n (\%) & $22(21.6)$ \\
\hline Others, n (\%) & $10(9.8)$ \\
\hline $\begin{array}{l}\text { Esophageal variceal bleeding } \\
\text { in the last year, } \mathrm{n}(\%)\end{array}$ & $53(52.0)$ \\
\hline Ascites in the last year, $\mathrm{n}(\%)$ & $72(70.6)$ \\
\hline Bilirubin $(\mathrm{mg} / \mathrm{dL}) *$ & $1.68 \pm 1.31$ \\
\hline Albumin $(\mathrm{g} / \mathrm{dL})^{*}$ & $3.67 \pm 0.65$ \\
\hline INR* & $1.56 \pm 2.59$ \\
\hline \multicolumn{2}{|l|}{ Cardiovascular risk } \\
\hline Diabetes, n (\%) & $58(56.9)$ \\
\hline Hypertension, n (\%) & $43(42.2)$ \\
\hline Handgrip strength $(\mathrm{kgf})^{\star}$ & $28.21 \pm 10.12$ \\
\hline
\end{tabular}

*Meantstandard deviation. HCV: hepatitis C virus; NAFLD: nonalcoholic fatty liver disease; INR: international normalized ratio. patients, there was an association between $\mathrm{EBBS}_{\mathrm{BEN}}$ and the presence of cardiovascular risks (95\%CI 0.005-0.096, $\beta=0.05$, $\mathrm{p}=0.03$ ) with no association with $\mathrm{EBBS}_{\mathrm{BAR}}$.

Considering EBBS responses, both groups presented high perceived benefits for physical activity. Mean $\mathrm{EBBS}_{\mathrm{BEN}}$ was 96.53 (SD 9.15) in the group with ascites, and the domains with the highest agreement percentage ( $\geq 95 \%$ ) were biological aspects, physical performance, and psychological aspects. Mean $\mathrm{EBBS}_{\mathrm{BEN}}$ was 100.29 (SD 9.2) in the group without ascites, and the domains with the highest agreement percentage $(\geq 95 \%)$ were biological aspects and physical performance. Individuals without decompensation had a higher agreement percentage $(\geq 80 \%)$ in the preventive health domain. When compared, the

Table 2. Generalized linear regression analysis of factors associated with EBBS Benefits and EBBS Barriers.

\begin{tabular}{|c|c|c|c|}
\hline & \multirow{2}{*}{$\begin{array}{c}\text { EBBS } \\
\text { Benefits } \\
\text { Univariate } \\
\end{array}$} & \multicolumn{2}{|c|}{$\begin{array}{c}\text { EBBS } \\
\text { Barriers }\end{array}$} \\
\hline & & Univariate & Multivariate \\
\hline & $\beta(95 \% \mathrm{Cl})$ & $\beta(95 \% \mathrm{Cl})$ & $\beta(95 \% \mathrm{Cl})$ \\
\hline Age & $\begin{array}{c}-0.001 \\
(-0.002- \\
0.001)\end{array}$ & $\begin{array}{c}-0.001 \\
(-0.006- \\
0.004)\end{array}$ & - \\
\hline Sex (female) & $\begin{array}{c}-0.008 \\
(-0.047- \\
0.030)\end{array}$ & $\begin{array}{c}0.057 \\
(-0.044- \\
0.159)\end{array}$ & - \\
\hline Bilirubin & $\begin{array}{c}0.000 \\
(-0.015- \\
0.014)\end{array}$ & $\begin{array}{c}-0.034 \\
(-0.071- \\
0.004)^{\star}\end{array}$ & - \\
\hline Albumin & $\begin{array}{c}0.014 \\
(-0.016- \\
0.044)\end{array}$ & $\begin{array}{c}0.035 \\
(-0.054- \\
0.124)\end{array}$ & - \\
\hline INR & $\begin{array}{c}-0.022 \\
(-0.066- \\
0.021)\end{array}$ & $\begin{array}{c}0.081 \\
(-0.032- \\
0.194)\end{array}$ & - \\
\hline HGS & $\begin{array}{c}0.000 \\
(-0.002- \\
0.002)\end{array}$ & $\begin{array}{c}-0.004 \\
(-0.009- \\
0.001)^{\star}\end{array}$ & - \\
\hline Ascites & $\begin{array}{c}-0.038 \\
(-0.079- \\
0.003)^{*}\end{array}$ & $\begin{array}{c}0.110 \\
(0.003- \\
0.217)^{\star}\end{array}$ & $\begin{array}{c}0.110 \\
(0.003- \\
0.217)^{\star}\end{array}$ \\
\hline $\begin{array}{l}\text { Esophageal } \\
\text { variceal } \\
\text { bleeding }\end{array}$ & $\begin{array}{c}-0.030 \\
(-0.067- \\
0.008)\end{array}$ & $\begin{array}{c}0.065 \\
(-0.034- \\
0.164)\end{array}$ & - \\
\hline $\begin{array}{l}\text { Cardiovascular } \\
\text { risks }\end{array}$ & $\begin{array}{c}0.022 \\
(-0.018- \\
0.062)\end{array}$ & $\begin{array}{c}0.059 \\
(-0.047- \\
0.165)\end{array}$ & - \\
\hline
\end{tabular}

Cl: confidence interval; INR: international normalized ratio; HGS: handgrip strength. ${ }^{*} p<0.05$ (univariate) and ${ }^{*} p<0.10$ (multivariate). 
Table 3. Sociodemographic and clinical characteristics of the groups with and without ascites.

\begin{tabular}{l|c|c} 
Variable & $\begin{array}{c}\text { Without } \\
\text { ascites }(\mathrm{n}=72)\end{array}$ & $\begin{array}{c}\text { With ascites } \\
(\mathrm{n}=30)\end{array}$ \\
\hline Age & $58.76 \pm 11.12$ & $60.23 \pm 9.27$ \\
\hline Gender & \multicolumn{2}{|c}{} \\
\hline \multicolumn{1}{|c}{ Male (\%) } & $45(62.5)$ & $17(56.7)$ \\
\hline \multicolumn{1}{|c}{ Female (\%) } & $27(37.5)$ & $13(43.3)$ \\
\hline Child-Pugh A (\%) & $52(72.0)$ & $7(23.0)$ \\
\hline Child-Pugh B/C (\%) & $20(28.0)$ & $23(77.0)$ \\
\hline Bilirubin (mg/dL) & $1.66 \pm 1.27$ & $1,74 \pm 1.42$ \\
\hline INR & $1.58 \pm 3$ & $1,53 \pm 0.64^{*}$ \\
\hline Handgrip strength & $30.46 \pm 10.32$ & $22,83 \pm 7.3^{*}$ \\
\hline $\begin{array}{l}\text { Esophageal variceal } \\
\text { bleeding (\%) }\end{array}$ & $29(40.3)$ & $20(66.7)$ \\
\hline $\begin{array}{l}\text { Cardiovascular risks } \\
\text { (\%) }\end{array}$ & $49(68.0)$ & $21(70.0)$ \\
\hline
\end{tabular}

Data represented as mean \pm standard deviation. INR: international normalized ratio; * $\mathrm{p}<0.05$

perception of benefits in biological aspects and physical performance domains were higher in the group without ascites.

$\mathrm{EBBS}_{\text {BAR }}$ mean was 31.47 (SD 7.83) in the group with ascites and 28 (SD 7) without ascites. For both, the highest perception was the physical effort domain, with an agreement greater

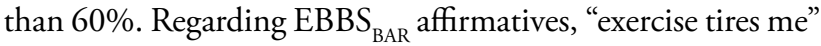
showed $80 \%$ agreement in the group with ascites and $68 \%$ in the group without ascites. In the statement "I am fatigued by exercise" there was $73 \%$ agreement in the group with ascites and $70 \%$ in the group without ascites. When comparing barriers perception in the exercise and environment domains, it was higher in the group with ascites.

When mean scores were compared, patients with ascites decompensation perceived greater barriers to physical activity (28.5 \pm 7 versus $31.4 \pm 7 ; \mathrm{p}=0.04$ ), while those without ascites decompensation perceived greater benefits to physical activity (96.5 \pm 9 versus $100 \pm 9$; $\mathrm{p}=0.04$ ).

\section{DISCUSSION}

To our knowledge, this is the first study to address factors associated with perceived benefits of and barriers to physical activity in patients with liver cirrhosis. The main study findings show that patients who had ascites in the last year had different perceived benefits of and barriers to physical activity than those who did not.
The natural history of liver cirrhosis is marked by a phase termed "compensated", evidenced by being asymptomatic, where portal pressure may be normal or below the threshold level identified for the development of varicose veins or ascites. There is a second phase termed "decompensated cirrhosis" in which portal pressure increases and liver function decreases with the progression of the disease, resulting in several complications ${ }^{16}$. Ascites occur at the rate of $6-7 \%$ annually so that after a decade, $60-70 \%$ of cirrhosis patients will have developed ascites ${ }^{17}$. Besides ascites, other complications are expected with the progress of the disease. The incidence of malnutrition increases with the progression of liver failure and is reported in approximately $20 \%$ of individuals with compensated cirrhosis and in more than $80 \%$ in decompensated cirrhosis ${ }^{18}$. A reduction in muscle mass, strength, and function, called "sarcopenia", is an important adverse clinical consequence observed in liver cirrhosis ${ }^{19}$.

Our results showed that the group with ascites presented reduced HGS (22.83 \pm 7.3$)$ compared to the group without ascites (30.45 \pm 10.32$)$. The degree of malnutrition is frequently masked by the presence of ascites in cirrhosis patients ${ }^{20}$. Measurement of HGS is a valid, simple, rapid, inexpensive method for investigating nutritional status. The Japan Society of Hepatology proposed that is one of the key criteria for evaluating liver cirrhosis $^{21}$. Although there are no pre-established benchmarks for cirrhosis, some recent studies have reported values that help in this evaluation ${ }^{21,22}$. In this group, patients with lower handgrip strength perceived greater barriers to physical activity, while those with higher strength perceived greater benefits. Alterations in the musculoskeletal system lead to reduced physical performance, disability, increased risk of related injuries, and frailty ${ }^{23}$. Thus, it is understandable that perceived benefits of and barriers to physical activity have been related to greater or lesser muscle strength.

The findings of Naseer et al. (2019) suggest that changes in muscle mass and strength are potentially modifiable in cirrhosis with exercise $\mathrm{e}^{24}$. Other trials also related exercise to improved functional capacity, quality of life, fatigue, and reductions in hepatic venous portal gradient, without adverse events ${ }^{25}$. Considering that muscle strength in patients with ascites was associated with perceived benefits and barriers, we suggest that, in addition to the guidelines on the importance of physical activity and participation in physical training programs, these individuals should also be followed up for their longitudinal strength measure. Since force is a marker for comorbidity and mortality, this measure should not be neglected and should be a routine approach in clinical practice. In addition, interventions such as increased physical activity to reduce the symptoms and fragility of these individuals imply an improvement in the quality of life and reduced symptoms of decompensated 
cirrhosis, tending to decrease the financial burden of the patient, the caregivers, and the health system ${ }^{20}$.

Greater benefits of physical activity were still perceived by those who had diabetes and/or associated hypertension in the group without ascites. These individuals also had a higher agreement in the preventive health domain, which includes prevention of heart problems, prevention of high blood pressure, and longevity with the practice of physical activity, demonstrating greater perception of morbidity and mortality. For several chronic diseases, accumulated evidence has led to the development of exercise-based rehabilitation programs with government funding 25 . It is possible, that these patients may have better-perceived benefits because they are assisted by a multidisciplinary team due to the presence of cardiovascular risks. Although there are few guidelines for physical activity in liver cirrhosis, this is a consolidated recommendation for the clinical treatment of hypertension and diabetes ${ }^{7}$.

Some limitations were present in the study: $i$ ) it was an observational study, requiring longitudinal studies that demonstrate that complications cause negative behaviors and perceptions related to physical activity; ii) although this was not the objective of the study, there was no qualitative assessment of barriers and benefits reported by the patients; and iii) a relatively small number of patients in the group that presented ascites in the last year leading to the possibility of a type II error for the studied variables, this limitation was due to the complexity to find outpatients with more severe cirrhosis.

We identified an influence of previous or current ascites decompensation concerning the perceived benefits of and barriers to physical activity. Patients with ascites, but with greater handgrip strength, identified more benefits perceived to physical activity. Individuals without ascites in the last year and the presence of cardiovascular risks were also associated with the perception of greater benefits for physical activity. The recognition of factors associated with perceived benefits of and perceived barriers to physical activity in patients with liver cirrhosis points to alternatives for interventions that allow changes in lifestyle and management of these patients.

\section{CONCLUSION}

In conclusion, the results of our study show that the EBBS Brazil presented good reliability in liver cirrhosis patients, and for the patients with ascites, the perception of the benefits of physical activity was positively associated with muscle strength while the perception of barriers was negatively associated with muscle strength. In the group without ascites the perception of the benefits of physical activity was associated with the presence of cardiovascular risks. These findings are important elements that should be considered to encourage increased physical activity in this population.

\section{AUTHOR'S CONTRIBUTION}

MRS: Data Curation, Investigation, Project Administration, Writing - Original Draft. FHLP: Conceptualization, Funding, Resources, Formal Analysis, Visualization. TML: Data Curation, Investigation, Project Administration. DMNH: Data Curation, Investigation, Project Administration. PACM: Conceptualization, Methodology, Funding, Resources. TMDO: Data Curation, Investigation, Project Administration. CCO: Investigation, Project Administration, Conceptualization, Resources, Supervision, Visualization, Writing - Review \& Editing. ASA: Conceptualization, Funding Acquisition, Project Administration, Resources, Supervision, Visualization, WritingReview \& Editing. CM: Conceptualization, Funding Acquisition, Project Administration, Resources, Supervision, Visualization, Writing - Review \& Editing.

\section{REFERENCES}

1. Flamm, SL. Diagnosis of cirrhosis and evaluation of hepatic encephalopathy: common errors and their significance for the PCP. J Fam Pract. 2017;66(4 Suppl):S34-9. PMID: 28375406

2. Asrani SK, Devarbhavi H, Eaton J, Kamath PS. Burden of liver diseases in the world. J Hepatol. 2019;70(1):151-71. https:// doi.org/10.1016/j.jhep.2018.09.014

3. Blachier M, Leleu H, Peck-Radosavljevic M, Valla DC, RoudotThoraval F. The Burden of liver disease in Europe: a review of available epidemiological data. J Hepatol. 2013;58(3):593-608. https://doi.org/10.1016/j.jhep.2012.12.005

4. Singh $\mathrm{H}$, Fujii LL, Murad MH, Wang Z, Asrani S, Ehman RL, et al. Liver stiffness is associated with risk of decompensation, liver cancer, and death in patients with chronic liver diseases: a systematic review and meta-analysis. Clin Gastroenterol Hepatol. 2013;11(12):1573-84.e1-2;quiz.e88-9. https://doi. org/10.1016/j.jhep.2012.12.00510.1016/j.cgh.2013.07.034

5. Ney M, Gramlich L, Mathiesen V, Bailey RJ, Haykokwsky M, Ma Mang, et al. Patient-perceived barriers to lifestyle interventions in cirrhosis. Saudi J Gastroenterol. 2017;23(2):97-104. https:// doi.org/10.4103/1319-3767.203357

6. Tandon P, Ismond KP, Riess K, Duarte-Rojo A, Al-Judaibi B, Dunn MA, et al. Exercise in cirrhosis: translating evidence and experience to practice. J Hepatol. 2018;69(5):1164-77. https://doi.org/10.1016/j.jhep.2018.06.017

7. Moore G, Durstine JL, Painter P. ACSMS's exercise management for persons with chronic diseases and disabilities. 4th ed. Illinois: Human Kinetics; 2016. 440 p. 
8. Kappus MR, Mendoza MS, Nguyen D, Medici V, McClave SA. Sarcopenia in patients with chronic liver disease: can it be altered by diet and exercise? Curr Gastroenterol Rep. 2016;18(8):43. https://doi.org/10.1007/s11894016-0516-y

9. Aamann L, Dam G, Rinnov AR, Vilstrup H, Gluud LL. Physical exercise for people with cirrhosis. Cochrane Database Syst Rev. 2018;12(12):CD012678. https://doi.org/10.1002/14651858. CD012678.pub2

10. Dumith SC. Proposal of a theoretical model for the adoption of physical activity practice. Rev Bras Ativ Saude. 20012;13(2):110-2. https://doi.org/10.12820/rbafs.v.13n2p110-120

11. Child CG. Childpugh score for cirrrhosis mortality [Internet]. [cited on Aug. 8, 2019]. Available from: https://www.mdcalc. com/child-pugh-score-cirrhosis-mortality.

12. Victor JF, Ximenes LB, Almeida PC. Reliability and validity of the exercise benefits/barriers scale in the elderly. Acta paul. enferm. 2012;25(1):48-53. https://doi.org/10.1590/S010321002012000800008

13. Brown SA. Measuring perceived benefits and perceived barriers for physical activity. Am J Health Behav. 2005;29(2):107-16. https://doi.org/10.5993/ajhb.29.2.2

14. Buchard B, Boirie Y, Cassagnes L, Lamblin G, Coilly A, Abergel A. Assessment of malnutrition, sarcopenia and frailty in patients with cirrhosis: which tools should we use in clinical practice? Nutrients. 2020;12(1):186. https://doi.org/10.3390/ nu12010186

15. Fess EE, Moran CA. Clinical assessment recommendations. American Society of Hand Therapists. Minneapolis: University of Minnesota Press; 1981

16. D'Amico G, Garcia-Tsao G, Pagliaro L. Natural history and prognostic indicators of survival in cirrhosis: a systematic review of 118 studies. J Hepatol. 2006;44(1):217-31. https:// doi.org/10.1016/j.jhep.2005.10.013
17. Neong SF, Adebayo D, Wong F. An update on the pathogenesis and clinical management of cirrhosis with refractory ascites. Expert Rev Gastroenterol Hepatol. 2019;13(4):293-305. https:// doi.org/10.1080/17474124.2018.1555469

18. Teiusanu A, Andrei M, Arbanas T, Nicolaie T, Diculescu M. Nutritional status in cirrhotic patients. Maedica (Bucur). 2012;7(4):284-9. PMID: 23483873.

19. Anand AC. Nutrition and muscle in cirrhosis. J Clin Exp Hepatol. 2017;7(4):340-57. https://doi.org/10.1016/j.jceh.2017.11.001

20. Vidot H, Bowen DG, Carey S, McCaughan GW, Allman-Farinelli $M$, Shackel NA. Aggressive nutrition intervention reduces ascites and frequency of paracentesis in malnourished patients with cirrhosis and ascites. JGH Open. 2017;1(3):92-7. https://doi. org/10.1002/jgh3.12016

21. Hanai T, Shiraki M, Imai K, Suetsugu A, Takai K, Moriwaki H, et al. Reduced handgrip strength is predictive of poor survival among patients with liver cirrhosis: a sex-stratified analysis. Hepatol Res. 2019;49(12):1414-26. https://doi.org/10.1111/hepr.13420

22. Tandon P, Low G, Mourtzakis M, Zenith L, Myers RP, Abraldes $J G$, et al. A model to identify sarcopenia in patients with cirrhosis. Clin Gastroenterol Hepatol. 2016;14(10):1473-80. e3. https://doi.org/10.1016/j.cgh.2016.04.040

23. Lang T, Streeper T, Cawthon P, Baldwin K, Taaffe DR, Harris TB. Sarcopenia: etiology, clinical consequences, intervention, and assessment. Osteoporos Int. 2010;21(4):543-59. https:// doi.org/10.1007/s00198-009-1059-y

24. Naseer M, Turse EP, Syed A, Dailey FE, Zatreh M, Tahan V. Interventions to improve sarcopenia in cirrhosis: a systematic review. World J Clin Cases. 2019;7(2):156-70. https://doi. org/10.12998/wjcc.v7.i2.156

25. Tandon $\mathrm{P}$, Ismond KP, Riess K, Duarte-Rojo A, Al-Judaibi B, Dunn MA, et al. Exercise in cirrhosis: translating evidence and experience to practice. J Hepatol. 2018;69(5):1164-77. https://doi.org/10.1016/j.jhep.2018.06.017 